\title{
SIII
}

Studies in Second Language Learning and Teaching

Department of English Studies, Faculty of Pedagogy and Fine Arts, Adam Mickiewicz University, Kalisz

\section{Adversity and redemption: Learning and teaching in the language learning histories of two EFL student-teachers}

\author{
Miri Tashma Baum \\ Givat-Washington Academic College of Education, Israel \\ mirimtb@gmail.com
}

\begin{abstract}
A better understanding of the multifaceted, dynamic and situated identity of the language learner stands at the center of much current SLA research. One of the main ways in which it is investigated is through the examination of autobiographical language learning histories. In an effort to better understand some of the processes which lead to a motivated, confident and successful language learner and user, this article analyzes the language learning histories of two EFL student-teachers, notable for their commitment to the learning and teaching of English. A close analysis of their narratives, focusing on thematic, stylistic and performative aspects, reveals what narrative psychologist McAdams (2006) has called "redemptive" patterns, that is, narrative structures in which hardship leads to inner growth and difficulties become "springboards" (Pals, 2006) to success. The two narrators also display a similar flexibility in their evolving self-positioning in response to the difficulties they narrate, and for both, attachment to the imagined community of Anglophone popular culture is an essential component in this process. Together, the learning experiences delineated in the accounts support the call for student-focused pedagogy, which puts emphasis on creating a positive emotional atmosphere, on the one hand, and providing rich intercultural knowledge, on the other.
\end{abstract}

Keywords: identity, language learning, autobiographies, narratives, motivation, agency, self-positioning, Israel 


\section{Introduction}

At the recent conference on Psychology and Language Learning in Graz, Austria (May 2014), integrative perspectives on the self set the tone for many of the presentations. It is now widely recognized that the learner should be regarded as a complex and dynamic whole, her identity ${ }^{1}$ continually shaped and reshaped by her interaction with her environment, and that all the aspects making up identity-cognitive, affective, physical and social-have a bearing on other language-learning concerns such as motivation, self-efficacy, and the internalization of language learning. As Dörnyei (2014b), drawing on the work of narrative psychologists such as McAdams $(2001,2006)$, Bruner $(1987,1991,2002)$ and Polkinghorne $(1988,1990)$, suggested in his keynote speech at the conference, the analysis of autobiographical language learning histories (LLHs) can be useful in exploring the evolving identities of learners, the sources of, obstacles to, and development of their motivation, and the possibilities for promoting future success.

This paper seeks to explore the identity of two English-as-a-foreign-language (EFL) student-teachers, both already teaching, whose LLHs display some of the complex ways in which identity is reflexively shaped in interaction with changing social and cultural circumstances. A close analysis of their two narratives, taking into account thematic, structural and performative elements (Riessman, 1993), reveals that, while the stories are different in many thematic and stylistic details, developing as they do out of different and unique sets of changing circumstances, the narratives share some central salient themes. Both narratives focus on difficulties in childhood/adolescence coupled with a "redemptive" (McAdams, 2006) approach to these difficulties. For both, the entry into the profession of teaching retrospectively turns these difficult memories into what Pals (2006) has called "springboards" to success. The two interviewees also describe a similar flexibility in their self-positioning in response to the difficulties they narrate, so that they manage to separate the weakening or potentially "contaminating" (McAdams \& Bowman, 2001) aspects of their experience from those which contribute to their language growth and identity enhancement. For both, attachment to the imagined community of Anglophone popular culture is an essential component in this process. The two interviewees thus present a picture of the growth of a language learner and user, in stories which contain both experiences of setback and, increasingly, empowerment and well-being, throwing light on sometimes unexpected sources of motivation and learner autonomy, with interesting pedagogical implications.

\footnotetext{
${ }^{1}$ In this study I will be using the feminine form of the pronoun to denote nonidentified subjects as this fits more closely with the research in which both interviewees are female.
} 


\section{Theoretical framework}

\subsection{The complex self of the language learner}

Ever since the "social turn" (Block, 2007), there has been a growing interest in second language acquisition (SLA) research in the identity of the language learner. There has been a shift towards holistic perspectives, focusing on individual learners, and a growing awareness of the complexity and dynamism of the language learner's identity and experiences across different times and contexts (Mercer, Ryan, \& Williams , 2012; Mercer, 2014). Thus, Ushioda (2009) calls for considering L2 learners as "persons-in-context," whose motivation for language learning can only be understood within the context of their identity as particular human beings feeling, wishing, and acting in multiple micro- and macro-contexts (p. 220). Mercer (2014) has argued for researching the language learner's sense of self from a complexity perspective, according to which "the self can be understood as an ongoing process that is never completed, but is continually in a state of development and self-organising emergence" (p. 177). Drawing on poststructuralist theory, researchers such as Norton $(2013,2014)$ and Pavlenko $(2002,2003)$ have shown how changing power relations affect the learner's identity, including her language learning motivation. Describing identity as "multiple, changing, and a site of struggle," Norton (2014) argues that affective descriptors such as motivated and unmotivated are "constructed in frequently inequitable relations of power . . . variable over time and space, and sometimes coexisting in contradictory ways within a single individual" (p. 73).

The different levels of motivation within an individual reflect the different identity positions she may hold. According to Norton, "language learners who struggle to speak from one identity position ... may be able to . . claim alternative identities from which to speak, listen, read, or write. If learners are successful in their bids for more powerful identities, their language acquisition may be enhanced" (2014, p. 74). In this conceptualization of multiple identity positions, Norton draws upon Davies and Harré's (1990) positioning theory (Norton, 2014, pp. 77-78), which claims that the discursive practices in which the individual participates continually provide her with "subject positions" (Davies \& Harré, 1990, p. 46) through which her identity is formed.

There can be interactive positioning in which what one person says positions another. And there can be reflexive positioning in which one positions oneself . . . One lives one's life in terms of one's ongoingly produced self, whoever might be responsible for its production. (p. 48) 
One of the processes by which the self is produced is the recognition of one's position as member of certain groups: "This recognition entails an emotional commitment to the category membership and the development of a moral system organised around the belonging" (p. 47). As Pavlenko and Norton (2007) show, one way in which individuals can achieve a powerful language-learning identity in addition to, and possibly bypassing, the traditional position of the classroom student, is through identifying with an imagined community of target language speakers: "Our orientation toward such imagined communities might have just as much impact on our current identities and learning as direct involvement in communities of our everyday life" (Pavlenko \& Norton, 2007, p. 670). As shall be seen, such identification has been central in my interviewees' adoption of identity positions, which have allowed them to withstand the debilitating effects of inhibiting learning environments and succeed in their language learning efforts.

\subsection{Narrative and the redemptive self}

Dörnyei (2014b) has recently persuasively argued that a better understanding of the complex makeup of language learners can be achieved through the study of their autobiographical LLHs. As Mercer (2013) notes, "as such, narratives represent a valuable form of qualitative data which can challenge simplistic, reductionist, abstracted, static, linear thinking about language learning processes and learners themselves" (p. 167). In many recent SLA studies, the multifaceted experience of language learning is indeed approached through narrative inquiry (cf. Benson \& Nunan, 2005; Coffey, 2013; Kalaja, Menezes, \& Barcelos, 2008; Mercer, 2013; Norton, 2000; Oxford, 1995; Pavlenko, 2001, 2003, 2007; Tse, 2000). The stories reveal the complexity, diversity and situatedness of language learners and language learning, and their inherently temporal structure foregrounds the essentially dynamic character of the language learning process.

The appreciation of the full significance of autobiographical creation involves the awareness that the connection between the narrative and the qualities and experiences of its narrator goes deeper than simply the reflection of the latter by the former. Leading sociologists such as Giddens (1991) and Bauman (2001), and psychologists such as McAdams (1993, 2001, 2006), Bruner (1987, 1991), and Polkinghorne (1988, 1990), have argued that our sense of identity as such is the product of the tale we continually spin out of the multitude of strands which form our experience. Giddens (1991) defines self-identity as, "the self as reflexively understood by the person in terms of her or his biography" (p. 53); Bruner (1987) claims that, "we become the autobiographical narratives by which we 'tell about' our lives" (p. 15). Addressing the challenges of identity-construction in the postmodern world, in which a "wild mix of cultural 
narratives and discourses determines a person's identity from one moment to the next" (McAdams, 2001, p. 115), McAdams claims that, nonetheless, "the naturally integrative power of narrative ... can bring together disparate features and tendencies in a given life into a more or less unifying and purpose-giving whole" (p. 116), so that while no one narrative can capture a person's identity, "people create unity and purpose in their lives, and they make sense of the psychosocial niches they inhabit in adulthood through stories" (p. 117). Thus, the construction of a "narrative identity" becomes a process which creates for the postmodern individual, dynamic and multiply positioned as she is, a sense of coherence through time, endowing the evolving life with meaning and purpose (McAdams, Josselson, \& Lieblich, 2006, p. 5).

McAdams (2006) pays particular attention to the pattern of the "redemptive" narrative, "stories of upward mobility, liberation, recovery, atonement, and self-actualization" (Bauer, McAdams, \& Pals, 2008, p. 96) in which "the intrinsically motivated protagonist overcomes intense suffering to experience an enhanced status or state" (Bauer et al., p. 96). These are contrasted with "contaminating" narratives in which negative experiences are described as reversing positive processes (McAdams, 2006). "Redemptive selves" (McAdams, 2006) are those individuals whose narrative identities generally follow the redemptive pattern. The episodes they choose to include in their life stories, and particularly those memories - high points, low points and turning points-which they have "privileged for self-definition" (McAdams, 2001, p. 110), create a narrative in which good follows bad, and personal suffering is redeemed in a commitment to those less fortunate. As we are the story we tell, those who structure their story in this way have indeed, argues McAdams (2006), a higher chance of achieving well-being, fulfillment, and generativity.

Further developing this idea, Pals (2006) writes about the "springboard effect" as the richest instance of the redemptive sequence. The springboard effect "redeems the worst aspects of past experience, the experiences that pose a direct threat to the coherence of self-making and the construction of growth" (p. 195). It is achieved through "the active, interpretive efforts of the individual to make meaning of the experience and causally connect it to the self" (p. 195), creating a clear causal link between past difficulties and present understanding and accomplishment. The springboard effect results in both achievement-related success and integrative benefits such as "empathy, generativity, wisdom, and an overarching clarity of meaning and purpose in life" (p. 196).

As Dörnyei (2014b) has argued, the understanding of the connection between the life story one chooses to tell and one's eventual success is valuable to language educators. LLHs do not only express the learner's identity; positive "emplotments" (Polkinghorne, 1988, p. 151) of life events can reconfigure past 
difficulties in self-empowering and future-directed ways, leading to self-fulfillment and success. As shall be shown, the narratives recounted by my two interviewees are characterized by a redemptive pattern and display the springboard effect in the causal links they create between incidents of helplessness and humiliation in the past and a present teacher identity characterized by efficacy, empathy and generativity, and an enduring sense of purpose.

\section{Methodology}

\subsection{Data collection and analysis}

In endeavoring to reach a deeper understanding of learners' experiences of their English education and the way in which it may become an enriching and empowering element in their evolving identity, I have undertaken a close analysis of the LLHs of two student teachers studying for an EFL teaching certificate in a teacher training college in the south of Israel. These histories were narrated in the course of in-depth semi-structured interviews conducted as part of a research project exploring the meaning of English for EFL student-teachers in the area, in which 19 students were interviewed altogether (Tashma Baum, 2014). Each student was interviewed once. The two students whose narratives I bring here had not met me previously although they knew of my position as the head of an EFL department similar to their own, in a neighboring college. Each interview lasted for about an hour and was conducted in Hebrew to ensure the maximum expressive ability of the interviewees, who were native Hebrew speakers. They were recorded, professionally transcribed, and then translated into English by me. The interviewees gave their informed consent to the research, and their anonymity was assured through the use of pseudonyms and the removal of identifying data from the texts prior to publication. While acknowledging the difficulty, if not the impossibility, of maintaining objectivity in my research, I believe that the organized mode of analysis (see below), the use of triangulation in comparing my findings with evidence from the different strands of the academic literature, and my prolonged engagement in the field will not only make the research trustworthy but will also allow some transferability (Creswell \& Miller, 2000; Lincoln \& Guba, 1985).

In the course of the interviews, the students related short stories, which they thus privileged as meaningful episodes within their learning trajectories (Coffey, 2013). Together, the stories told in the course of each interview formed the interviewee's LLH for the purpose of my research. The two interviews analyzed in this study were chosen for the richness of the narratives they produced 
(Cohler \& Hammack, 2006; Shoaib \& Dörnyei, 2005) and their clear demonstration of the redemptive approach and the springboard effect. In each interview, the interviewee produced a coherent, detailed plot (not always narrated chronologically), viewing her involvement with English as a story in which early emotional experiences-positive and negative-led to a complex positioning vis-àvis the language and speaking at length on the ways in which her current close relationship with the language emerged from this positioning.

In analyzing the two narratives, I have chosen a primarily holistic orientation (Lieblich, Tuval-Mashiach, \& Zilber, 1998). My main interest has been to follow the development of each LLH separately, as each is distinct in its particular interweaving of the social and the psychological and in the rhetorical strategies employed to create, maintain and project the unique narrative self. For this purpose, I deemed holistic life story analysis, focusing on thematic, structural and performative aspects (Riessman, 1993) particular to an individual, to be most suitable as only such a focus can do justice to the integrative nature of the stories, to the way they "bring together disparate features" (McAdams, 2001, p. 116). I hence considered each language autobiography separately. Guided at least in part by prior theory on identity and language-learning (presented above), but open to novel insights from the data (Riessman, 2008), I first noted all the salient thematic details connected with the encounter with and the changing attitude towards English, striving to always see these details within the context of the narrative story sequence as a whole (Riessman, 2008). I then focused on stylistic features of the text such as discourse markers, metaphors, repetitions, and tense and pronoun shifts. Stylistic features, perhaps less easy to consciously manipulate, can reveal much about the emotional aspects of the narrator's experiences (Lieblich et al., 1998). I also paid attention to performative aspects of the texts, taking account of ways in which the micro-context of the narrative, the interview situation, may have influenced the self-positioning of the narrator within her narrative (Riessman, 2008). Following this, I formulated my understanding of the main themes of each narrative, traced patterns of ascent and descent, and located Singer's (as cited in McAdams, 2001, p. 109) "self-defining memories" upon which the narrative turns.

While this "case-centered commitment," as Riessman (2008, p. 74) has called it, is at the center of my research, a comparison of themes in the two narratives; such as the importance of the imagined community, the nature of the turning point, the redemptive pattern, and the attitude towards teaching which derives from it; can also be fruitful (see Riessman, 2008). In the final section of my paper, I address some of the differences and similarities between the stories, and explore the pedagogical implications of some of the themes which the two have in common. 


\subsection{The research population}

Life stories are psychosocial texts that are jointly crafted by the individual himself . . . and the culture within which the individual's life has meaning. Our autobiographical stories reflect who we are, and they also reflect the world in which we live. (McAdams, 2001, p. 117)

Attention to time and place is central in any integrative approach, and it is one of the defining characteristics of narrative analysis (Riessman, 2008). A consideration of the social and cultural context within which the two narratives were formed is thus essential for a more complete understanding of their significance. The college in which my two interviewees studied belongs to Israel's southern district (Mehoz Darom), as do the towns and smaller communities in which the students lived and taught. A central characteristic of the demography of the South is its large percentage of Mizrahim, that is, Jews of Middle Eastern or North African extraction. The southern Mizrahi population is underprivileged both economically and academically, although the situation is gradually improving (Smooha, 2004). English is almost universally esteemed in Israel and a key to educational and professional advancement (Ben-Rafael, 1994). It has been found to be especially highly regarded by members of the lower socioeconomic strata, to which this population belongs and who often see it as the passport to an improved socioeconomic position (Ben-Rafael, 1994; Donitsa-Schmidt, 2004; Narkiss, 2002; Spolsky \& Shohamy, 1999).

The two participants in my study share the generational, gendered, socioeconomic and cultural milieu characteristic of the majority of students at their college: young Jewish women (in their early to late 20s), from a Mizrahi family background, of working-class or lower-middle-class economic status. Socioeconomic factors such as the relative inferiority of the educational system in the area (Smooha, 2004) can partially account for the interviewees' negative school experiences. Cultural factors such as the high symbolic value attached to English by the Mizrahi population can clarify its attractiveness for the students to some degree. The distance between ethnic Mizrahi culture, with its Arab roots, and the "Westernness" of Anglophone culture may help explain its allure as an exotic Other (Tashma Baum, 2014). I will now turn to the two LLHs, analyzing each in turn and following the ways in which they describe the evolution of their situated, dynamic, complex narrators, who are deeply affected by the sociocultural conditions in which they find themselves, but who can also affect and change these conditions, to an extent, and carve their own inspiring path. 


\section{3. "A jumping of the way": Shanit's story}

Shanit (a pseudonym) was 23 years old at the time of the interview. She was born and grew up in a small, socioeconomically weak town in the South and was still living there at the time of the interview. Since her father had worked abroad and her mother, a midwife, was of Jewish-Indian extraction, both her parents had some knowledge of English. She was married and expecting her first child. Although still a student, Shanit was already in her third year of English teaching, working at a prestigious elementary school in an affluent community some distance from her hometown.

In response to my first question, inviting Shanit to look back at her LLH, Shanit opens with a kind of abstract or summary (Riessman, 2005) in which she describes her deep and abiding love for English and ends with a "happy ending" in the form of marriage with an English speaker:

First of all, English is in my soul and always has been ... I've always had the enthusiasm for English. I'd watch films, hear songs in English, loved the language, loved the accent. By the way, I also married a South African in the end who speaks English as his mother tongue, so I taught him a bit of Hebrew, he knew a bit so I improved his Hebrew.

Shanit presents herself here as very assured, consistent and firm. Love of English is presented as a given from the start ("always") and is immediately linked with the products of anglophone popular culture: the films and the songs. Later on in the interview, Shanit elaborates on this, claiming that she had preferred "the American style" to local cultural offerings even in elementary school, where she and a friend were regarded as "cool" by the other girls for their ability to "do the slang, do the accent." At the present time, she still thinks that "American culture is more polite, more dignified, more intelligent when it comes to manners." Her marriage to an English-speaker thus seems the icing on the cake, as it were, of her lifelong attachment to the imagined community of English-speaking culture. Interestingly, however, the power remains firmly in her hands in the description of this union: She focuses not on her husband's superior knowledge of English but on her superior knowledge of Hebrew and positions herself as her husband's teacher. The parenthetical "by the way" which she adds before her mention of the husband is a further indication of her authoritative, controlling style: She has a clear grasp of the generic requirements of the narrative she has embarked on and is aware of the prolepsis or "flash-forwards" (Bruner, 1987, p. 29) she is performing, and she thus excuses it with a discourse marker signaling awareness of moving away from the main timeline. 
Having set this tone and returning to the time before the prolepsis, Shanit then self-consciously skips, following the transitional but, to an experience which totally unsettles the confident mood: her illiteracy in elementary school:

And I always loved but, I'm skipping a bit, but I didn't know . . I didn't, I didn't know how to read till the sixth grade. I didn't know how to read a word in English, and I loved English. I could still speak English fluently, I had a wide vocabulary, and I didn't know how to read, and no one helped me either, even when I had difficulties and stuff like that, I had no help.

Shanit signals her continuing control of the narrative with the acknowledgement: "I'm skipping a bit," indicating that her move to the painful childhood story is deliberate; as she is about to show, the roots of her present pedagogical principles are to be found there. Stylistically, repetitions dominate the account, pointing to the emotional charge of the events (Lieblich et al., 1998). The emotional tone suggests that this episode is central to Shanit's learning trajectory, as in the words of McAdams (2001), "emotion ... help[s] to organize events as goal-based stories" (p. 109). Here, the word most often repeated is the word no. The text is suffused with negativity, especially in connection with lack of knowledge, as illiteracy is presented as a wholly negative state, linked with feelings of helplessness and abandonment: "I didn't know . . I I didn't know . . . no one helped me ... I had no help."

This situation of lack, ignorance and passivity ends dramatically "one day," when Shanit's parents come to her aid. The description of this moment is, tellingly, immediately followed by an affirmation of Shanit's commitment to teaching:

Till one day my parents sat with me and gave me a kind of little course. And then they taught me the letters, and then I really ran with the English, from the sixth grade on I ran with the English, and then I really became prominent in English. But it's really really in my soul, even now when I teach something it's in my soul that the students will know, that they'll enjoy themselves. English is really a school subject I love. The principal always asks me ... if I want to teach another subject, and I told her no way, I want all my hours only in English, I'm not built to teach any other subject, it's simply a subject I truly truly love.

The moment in which aid is given is the turning point of Shanit's story. Her awareness of its centrality in the timeline can be felt in her three repetitions of the time adverb then to describe its outcomes. Her growing agency is accentuated with the repeated use of the active verb ran. These repetitions as well as the repeated use of intensifiers (really, truly) can again be a sign of heightened emotion (Lieblich et al., 1998). Shanit does not yet create a causal link between this memory and her present devotion to the teaching of English, but the juxtaposition 
of the two is the first sign that for Shanit, the memory is intimately connected with her present profession and self-identity.

As this memory seemed a deeply significant one, during the interview I asked for more information and received a more detailed narrative which brought into sharper focus the process by which Shanit first passively acquiesced and then rebelled against her illiteracy, taking charge of her own learning. The opening of this second account again reveals the close relationship between the past and present in Shanit's understanding of her story, now establishing a clear causal link between them:

Interviewer: How did it happen that you didn't know how to read till the sixth grade? What happened there?

Shanit: The truth is that I blame, not blame - but I see it as the negligence of the teacher. Because of that, because I didn't know how to read it's important to me. . . it was in my soul: every student in my care has to know how to read! No matter what, what price I have to pay... I'm not taking the responsibility that a student leaves the class without knowing how to read, because I know from my own experience that the third or fourth grade teacher overlooked me, you understand? Now a kid of his own initiative isn't going to start looking for people to teach him. . . As far as I was concerned, I didn't know so I didn't know, I continued like that another year and another year and another year and I guess my teacher overlooked me, and I, of my own initiative, of course a girl isn't going to start looking for a way to learn to read.

In this second, more detailed account, Shanit draws a causal link between her two positions of vulnerable student and dedicated, empathic teacher, showing how the latter evolved from the former in a process which weaves together moral and emotional aspects. The strong emotion and equally strong self-control characteristic of her narrative are evident in her opening, as she replaces direct accusation ("blame") with a more considered, professional-sounding criticism ("the negligence of the teacher") probably in accordance with her current position as an education professional. Shanit displays a strong sense of personal and professional responsibility throughout, and the "negligence" she describes offends her moral sensibility just as much as it has offended her feelings. The memory is then causally linked with her present day commitment to the literacy of her students: "Because of that, because I didn't know how to read it's important to me," and the sense of moral and, since she has become a teacher, professional outrage thus aids Shanit in turning her personal humiliation into a springboard for transformation and redemption. It provides her with the moral system, which, as Davies and Harré say, "links and legitimates the choices that are being made" (1990, p. 59). The moral stand is accompanied by a deep emotional identification with her students: "I'm not taking the responsibility that a 
student leaves the class without knowing how to read, because I know from my own experience that the third or fourth grade teacher overlooked me, you understand?," and the direct appeal heightens the emotional charge. This sense is then strengthened as she uses similar phrasing to describe her students' quandary: "A kid of his own initiative isn't going to start looking for people to teach him" and her own: "I, of my own initiative, a girl isn't going to start looking for a way to learn to read."

At this point, Shanit returns to the traumatic experience of ignorance, passivity and helplessness, which she describes as lasting from the third or fourth grade to the sixth, and provides valuable insight as to the self-positioning involved in the response to adverse educational experiences:" So as far as I was concerned I said ok, I don't know how to read. So I got along like that till I reached the sixth grade." Presenting the thoughts of her childhood self, Shanit reveals that active self-positioning is involved even in accepting a position of helplessness and deficiency. Here the child is accommodating herself to the situation by consciously adding the new information relayed to her by society to her ongoing understanding of her identity. This moment is brought as a direct quotation of inner speech: "ok, I don't know how to read," and the dramatization highlights its centrality: It is the moment in which inability is accepted as a given, as a quality of the self. The formulation also emphasizes the deliberateness of the positioning: Perhaps since this is such a moment of difficulty, as the child feels required to accept into her identity a position which, as a lover of American culture, she feels is alien and painful to her, the conscious effort of accommodating it is stressed. It is thus described as a deliberate self-defining speech act of declaration: "I don't know how to read," an utterance which in itself brings about the new situation (Crystal, 1997). The effect of this new positioning is devastating: Shanit then indeed "gets along," illiterate and helpless, till the sixth grade, and though she eventually rejects this position, the repeated return to this experience in the course of the interview suggests that it continues to haunt her, tarnishing her identity, as it were, even as she becomes a successful, proficient teacher.

The pattern of descent culminates in what Shanit experiences as extreme social degradation: her placement in a lower level group:

And then in sixth grade we were divided into proficiency-based groups . . and I really really love to learn, so I couldn't bear the fact that I was in Group B because I couldn't read, and I could speak better than everyone and had a better vocabulary than everyone. So I felt like on the one hand, I'm sitting in Group B and, like, smarter than everyone, you feel unfulfilled and you give the teacher all the answers, and on the other hand, you feel that your place isn't here, on the other hand, you want to get to Group A and you don't have the ability. 
In this version of the story, it becomes clear that the reason for taking action is an identity crisis, which Shanit can no longer "bear." Faulty pedagogical practices have created a situation in which Shanit is officially positioned as a weak student, a positioning which she has also internalized, as we saw, with regards to literacy. Now this positioning is given an official stamp of approval in her assignment to Group B, which causes it to clash more clearly with Shanit's ongoing self-positioning as proficient oral English user, a positioning enabled by her adherence to anglophone popular culture. In this emotional passage, replete with intensifiers and repetitions (really, better than everyone, on the other hand), Shanit describes her acute sense of being in the wrong place, yet unable to move to the right one. The crisis can be seen as social as well as psychological: Knowledge of English has given her a superior position among her classmates, and this precious social capital is now endangered. The shift to the second person pronoun and the present tense in the final sentence subtly add to her argument. Using you to stand in for the self, Shanit is presenting her plight as one with which all reasonable people can identify (see Labov, 2013, p. 41, on the self as generalized other) and one not limited to a particular instance in the past. She thus increases the importance and widens the relevance of her predicament, making it general rather than private and suggesting that she is also speaking from her current position as a morally-involved educator.

At this point, the turning-point takes place:

So that's really what ... gave me the "jumping of the way" to say to my parents, "Dad, I want to learn letters." He wrote me every letter with the sound, large letter, small letter, and we drew lines. I learnt to read. But many things I missed that I made up later. .. over the years, slowly, I learnt a bit myself. . . till I arrived where I arrived, thank God.

As Davis and Harré (1990) note, the agency of the individual manifests itself in resolving contradictory positionings: "to act rationally, those contradictions . . . must be remedied, transcended, resolved or ignored. . . . The possibility of choice in a situation in which there are contradictory requirements provides people with the possibility of acting agentically" (p. 59). Shanit here rejects one position and embraces another. She steers her self-identity away from the position of passive non-reader towards that of reader, with all the hard work which this entails, beginning with the first determined action of speaking to her father and actively asking for help, dramatized through direct quotation: "Dad, I want to learn letters." Shanit describes the results of this plea as a "jumping of the way," and the choice of expression is significant. A Jewish religious term, it refers to a magical, divinely-assisted shortening of a righteous person's journey. As Davies and Harré (1990) note, "the words the speaker chooses inevitably contain 
images and metaphors which both assume and invoke the ways of being that the participants take themselves to be involved in" (p. 49). The metaphor is significant for Shanit, appearing as it does at the turning point of her story. Not only does it link with the earlier description of her then "running with the material," forming a motif of learning as travelling a road, but it also lends to this journey a mystical, even religious tone, turning the study of English into a calling. Shanit's highlighting of this moment is part of her fashioning of an identity based on self-motivation, hard work, and a clear moral purpose. With the spiritual overtones she gives it, it becomes the cornerstone of her long process of ascent and redemption.

As the interview draws to a close, it remains clear that moral indignation and an enduring sense of betrayal remain a part of Shanit's identity as an English teacher but also that overall her professional identity, rooted so deeply in her personal story of trial and victory, is confident, generative and self-fulfilled. Bitterness is still clear when Shanit returns a final time to the story of her childhood trauma, in a moment which wholly conflates the past and present:

Bottom line, I take the responsibility for the English. If in the third grade they don't learn it from me, who will they learn it from? They'll develop a gap. I have kids in the sixth grade who don't know how to read, and I work with them the whole year, but how much can you work with them?. . . And I, like, look at the teacher, at the teacher who taught me in the third grade - where were you? Look, you overlooked four or five kids here! [Emphasis added]. So these four or five kids simply sit in my class and I have to bring them learning materials for the third grade, it's - it's - they're just miserable.

In the emphasized words, the incompetent teacher who neglected to teach Shanit's sixth-grade students when they were in the third grade has become one with the teacher who neglected to teach Shanit herself when she was at that age. By protesting the injustice done to the overlooked children, Shanit gives voice to her own childhood pain; by working with them devotedly, she confronts and helps heal that pain.

It thus seems that due to her redemptive approach, and particularly her ability to transform her most difficult language learning memories into a springboard for success, Shanit's current professional identity is a happy one:

I think I'm not like the other teachers. I simply go to work and I enjoy myself, I enjoy teaching. You know, in the third grade when they know how to read at the end of the year it's like for me - it's like, like I feel as though they're my children, and I've just taught them how to walk.

Shanit describes herself here, as elsewhere, as a successful, appreciated, fulfilled teacher. Her sense of accomplishment may also include a socioeconomic 
element: The school she teaches in caters to a population belonging to a much higher socioeconomic bracket than Shanit's, and her position of authority there may also involve the acquisition of social capital, in addition to her considerable professional satisfaction. Describing her sense of achievement when her students finally master reading, Shanit here uses a complex simile which tellingly reflects on her story. Her reflexive positioning as a mother makes use of a typical image of powerfulness in female discourse (Davies \& Harré, 1990) and fits Shanit's authoritative tone; it also links Shanit with the image of the one good teacher she describes in her narrative: her father. In addition, the motif of learning as travelling appears here one final time. Following the immobility of the years of illiteracy, Shanit had managed to "jump the way" and close the gap, "running" with the English all the way to college; now, the redemptive process reaches completion as she teaches her own young students "to walk" this rewarding path.

\section{4. "It affects everything": Tehila's story}

Tehila was 29 years old and unmarried at the time of the interview. Originally from the same town as Shanit, she was now living and working in a nearby town similar in size and socioeconomic bracket. Her mother was a cleaner at the local council and her father unemployed; neither of them knew English. Although still a student, she had been teaching English at the local high school for four years at the time of the interview and had recently been made the English coordinator at the school.

Like Shanit, Tehila's opening statement sets a tone of confidence and self-fulfillment, but the journey towards English teaching seems less deliberate than Shanit's:

I have to say that I love it very much. It's not something I expected to do or thought about in my past, and I'm very pleased that I rolled into this field, and that I find myself there and fulfill my future there, thank God.

To "roll" (lehitgalgel) here is a Hebrew idiom suggesting unintentional movement, "going with the flow," as it were. Tehila uses it again, as she continues to explain how she found herself teaching English:

When I was about 20, I flew to the US as an au-pair, before studying. I got stuck there for five years. I loved the community and the culture in general very much. I returned here to Israel, and a relative who's actually an English coordinator in a school asked me whether I could replace a teacher who was away on maternity leave ... because there was a big shortage of teachers at that time. And I went in for three months... and from there I started rolling with it. . . A year later they already asked me to teach. I was in the middle of my degree in human resource management, so I decided I would first finish my degree, and then do retraining in English, and now I'm in retraining. 
Tehila's use of passive verbs ("I got stuck there") and of formulations in which she is the recipient of the action ("a relative ... asked me," "they ... asked me") in order to describe the process by which she entered the profession she now deeply loves is quite striking. In fact the only agentic decision here is one opposed to this process: her decision to first complete her degree in human resource management. The reason for this may lie in Tehila's sensitivity to the interview context: Perhaps she is conscious of the interviewer's position as the head of an EFL department, and this causes her to use an apologetic tone in explaining how she is already teaching when she does not yet have a teaching certificate. An alternative or additional reason can be lingering feelings of inadequacy, and the source of these gradually becomes clear.

It is only following my request of Tehila to look back and elaborate on the beginnings of her love for English that she tells the painful episode at the heart of her story:

I didn't always love the school subject of English, I have to say, and because this is anonymous I feel more confidence to say, but when I was in high school, they did a diagnosis and claimed I had dyslexia in English. This was proven wrong eventually. But because I really loved watching movies, listening to songs and translating, I had a very wide vocabulary, but they never sat down and taught me reading properly. So as far as they were concerned then, that was considered dyslexia. It's just that in my case it was a gap in knowing how to read and write. That's why today I understand the struggling students that I teach better. And then I loved the language, I just didn't love the studying in class, so you can divide it into two fields.

As in Shanit's interview, the transition marker but opens the description of the difficult episode, then followed by two more buts intensifying the sense of jarring and contradiction. The experience described is also similar to Shanit's: Tehila reveals the dissonance between the education system's positioning of her as a weak student in English, based on her illiteracy, and her self-positioning as knower and lover of oral English. Even as she reveals this, Tehila impressively brings the two back together, creating a causal link by which she establishes the childhood distress as the springboard to her current success as a teacher of weaker students: "That's why today I understand the struggling students that I teach better."

This is not to say, however, that the revelation is an easy one. The anxiety it generates can be felt when Tehila draws sudden attention to the interview context, saying that she has the "confidence" to tell the story only because she knows it will be published anonymously. Possibly, she means by this that people who know her as a teacher will not discover the gap she is now exposing between her competent, positive professional self and her "faulty," alienated childhood self. Alternatively, she may be thinking that her report could be taken 
as criticism of the school system by future readers, in which case the revelation of her identity may place her in an uncomfortable position with coworkers and superiors. A third option is that she is legitimizing her criticism by positioning herself as an anonymous campaigner for educational improvement rather than someone conducting a personal vendetta, in which case the shift to a less "personal" positioning is somewhat similar to Shanit's as she moved away from personal "blame" to the more professional-sounding judgment of "negligence." Whatever the cause, Tehila is clearly indicating that the childhood self she is now revealing coexists uncomfortably with her social and professional position as English teacher, a lack of fit which requires the temporary removal of the latter (through maintaining anonymity), so that the former can appear. In this respect, the interview context is clearly liberating, allowing Tehila to make known formerly hidden aspects of her complex, changing identity, and to address, rather than suppress, contradictory and painful elements.

Now Tehila has to deal with the reality of illiteracy, which, like Shanit, she initially accepts. Interestingly, the pronouncers of the verdict of dyslexia, presumably the educational diagnostician, the school guidance counselor and the teachers involved, are referred to throughout the quoted passage above only as "they," and the pronoun distances them and makes their exact identity vague but by no means less threatening. Rather than individuals who can be approached, the educational authorities are positioned as a nameless, shapeless entity, negligent in performing its duties, on the one hand, and having immense power over the fate of children entrusted to its care, on the other. Tehila indeed submits to "their" verdict, unquestioningly incorporating it into her self-identity:

I really believed, I thought it was dyslexia, because I didn't understand that it was only a gap, because when people, you know, experienced people come and conduct an organized diagnosis, so you rely more on what the experienced people tell you, and sometimes you don't try to challenge yourself, but stay with their opinion.

Unlike Shanit, Tehila's low point does not directly lead her to the turning point and the start of the redemptive process. Faced by society's judgment in its most authoritative, legitimized form: "experienced people conducting an organized diagnosis," and perhaps also due to her different family circumstances, as her parents, unlike Shanit's, cannot provide her with an alternative learning environment, Tehila relinquishes all the agency she may have had in pursuing literacy. This is emphasized here in her choice of stative rather than dynamic verbs: She "believe[s]" in the verdict handed down by the school system, she "reli[es]" on its representatives, she "[doesn't] understand" the truth and "stay[s] with their opinion." Interestingly, as in Shanit's narrative, the confession of helplessness is 
given in the second person you, with similar effect: The underlying suggestion is that this is the only reasonable response possible under the circumstances (Labov, 2013). Faced with overwhelming judgment, Tehila ceases to "challenge [her]self' in this field, and reading seems to come to a dead end.

Under these conditions, the teenage Tehila demonstrates her agency and flexibility in maintaining two distinct identity positions, clearly separating the hated school topic from the beloved Anglophone culture. This separation is, in fact, an empowering, growth-enabling response. It allows Tehila to keep up her motivation to learn English, focusing mostly on songs and largely avoiding reading, uncontaminated by her disabling school experience. The situation recalls Norton's (2014) insight that motivation and investment in classroom learning are not necessarily linked: "A student can be highly motivated, but if the language practices of the classroom make a learner unhappy or dissatisfied, the learner may resist participation" (p. 84) as well as her assertion that the learner may claim alternative, more rewarding identity positions from which to learn. Tehila's affiliation with the imagined community conjured up by American music and cinema offers her such an identity and a motivating vision:

There was the dream of living in America . . . Me and my friend, we were two friends together, we both really wanted to visit New York and see a performance by Celine Dion, and that was the dream, yes. We didn't think of living there, but yes, that was the dream.

Dörnyei $(2009,2014 a)$ speaks of vision as a key motivational force in sustaining the long-term effort of language learning, and here we find it as a central element in Tehila's English-loving identity and a stimulus to action. It influences the next step of her learning trajectory, the action which initiates the redemptive process in her story: her trip to America.

The turning point in Tehila's narrative follows her momentous decision to visit the US, despite her illiteracy. There, in a positive, supportive environment, Tehila develops new identity positions which give her the impetus to teach herself to read in English. She takes the job of Hebrew-teaching au-pair with a Jewish family in a big American city, later working with other families and in the Jewish schools of the community, and stays there for five years. This period is described as very industrious and fulfilling, and the English-speakers-now no longer an imagined community but actual members of the local Jewish community- as warm and supportive: "I have very very good friends there and families I worked with, and we all became a part of one family." In an environment in which her social superiors are no longer "they" but rather "family," and physically removed from the educational system which had condemned her to passivity and helplessness, Tehila begins the process of redemption as she decides to "challenge [her]self" and learn to read: 
When I got there I faced the reading . . I I tried to challenge myself, that is, I would sit with the children doing homework, always in the beginning I would go to the safe place of Hebrew, because they were Jews, and sometimes I would say, let's try and help in English too, although I wasn't confident in that field. I also saw signs, I'd travel a lot, so I would take a map and see that I can actually get along with the reading, so in the beginning it wasn't reading stories, it was more sentences and signs, but after that I started reading newspapers a bit, and I succeeded more with the reading. . .

In this section of the interview, in which the passive roles Tehila had tended to assign to herself are suddenly replaced with agentic ones (Riessman, 2002), a number of elements seem to band together in motivating Tehila, and all are linked to her changing position within the society she has entered. Norton (2014) has shown that "the ways in which power is distributed in both formal and informal sites of language learning ... . and how it affects learners' opportunities to negotiate relationships with target language speakers" (p. 74) are central factors in determining the success of the language learning endeavor. Although her work as an au-pair suggests subservience, Tehila's additional role as Hebrew teacher to the children in her care gives her a position of some authority. Beginning with "the safe place of Hebrew," where she receives credit for her abilities in her field of expertise, Tehila gradually finds the courage to take on English from a position of teacher or helper rather than the inferior position of learner. As she concurrently becomes an independent traveler, in accordance with her childhood vision of visiting the country, reading becomes a tool for selffulfillment. She begins accumulating mastery experiences (Bandura, 1997): "I would take a map and see that I can actually get along with the reading," experiences which are the most influential source of self-efficacy (Mills, 2014). Thus, from a position of strength, fulfilling a childhood dream, positioned as language user rather than learner, and developing all-important self-efficacy beliefs, Tehila finally achieves the remarkable feat of autonomously learning to read English: from signs to maps to newspapers to stories.

It is, however, only upon returning to Israel and beginning work as a teacher that the pain of Tehila's high school misdiagnosis fully turns into a springboard for success. We have seen how Tehila's adolescent experiences caused her to wholly separate the attractive media aspects of English from the hated school subject. She now describes her own weak students similarly, as lovers of American popular culture who are nonetheless totally alienated from the language in its school setting. Her description of her pedagogical work with these students is tellingly concerned with bringing the two together:

One thing I try and work on particularly hard . . . is just to love the subject. I mean, they usually build walls of frustration . . for me just the fact that they understood 
that they can learn another language, and breaking down the walls [is important] . . . So I start with strategies which perhaps not all the teachers here accept . . I I show them on their IPhone, on the computer, they bring sentences which they came across on the computer and I say look, it's so useful . . . it's a language that will help you, there are signs today in Israel which are only in English... So if you want to advance yourself, you must start acquiring the tools to deal with English. I think this attitude makes them look at it a little differently . . . and then . . . the fact that they're succeeding in managing with the English, already makes them want it.

By leading these weak students to love the school subject of English, Tehila seems to be healing the painful split she herself had endured as a schoolgirl. Based on her own experiences, it seems, she positions the students as language users rather than learners, drawing their attention to the usefulness of the language for achieving goals relevant to them, and supplying them with mastery experiences which she knows will foster their self-efficacy. She also has particularly friendly ties with her students, later claiming that "because I'm comparatively young among the staff . . . I understand them . . . we have a very good relationship," reminiscent of the friendliness which characterized the American setting in which she herself found her motivation for literacy.

Interestingly, one can also detect in Tehila's descriptions a sense of defiance towards other teachers: "So I start with strategies which perhaps not all the teachers here accept," even though Tehila herself is now one of them. The separation of herself from the group is reminiscent of Shanit's claim that she is the only teacher at her school who enjoys teaching. This is perhaps another remnant of difficult schooldays experience: a lasting discomfort regarding the possibility of being positioned as a "regular" teacher, one of those threatening, insensitive figures of educational authority referred to only as "they" in Tehila's account of high school, and a need to distance oneself, as a different kind of educator, from them.

It is only towards the end of the interview, when I ask Tehila whether there is anything she feels it is important to add, that she gives the most passionate and direct expression to the darker side of her difficult past experiences, namely the threat such experiences pose for the development of a healthy identity:

It's really important to bring the right teachers to the profession. Because really I see students arriving in class very frustrated, and it's not their fault, and I'm one of them. And it has an effect, it affects everything, both the attitude to English and even other subjects, so that you no longer - you lose your confidence in yourself.

As also happened to Shanit, identification with the students becomes total here, in a moment conflating the past and present. In what may be a slip of the tongue, Tehila presents herself as one of her students: "and I'm one of them," 
so that the powerful pronouncement following this: "it affects everything . . . you lose your confidence in yourself" is about both herself and her students. The use of second person narrator here, you, suggests that this is also a general truth. English can clearly not be separated from other subjects of study, or indeed from one's identity as a whole: Poor teaching can result in losing "your confidence in yourself" as such. In Tehila's case, the passage proves that while she has clearly chosen the "redemptive" path, Tehila is not unaware of the other path she could have taken; her negative experience, she says, could have led her to lose all belief in herself, a classic pattern of "contamination" to use McAdams' term. The apologetic tone which we saw at the start of her interview, stressing her lack of agency in the process by which she ended up an English teacher, may indeed be, as I have suggested, a sign of a lingering sense of inadequacy. As it is, her full awareness of this danger makes Tehila's victory over this hurdle, her selfobtained mastery of English, and her current role as successful, growth-enabling teacher, all the more remarkable.

\section{Conclusion}

Placed side-by-side, the two narratives are different in many of their details, but there are also clear thematic similarities in the narrators' responses to their adverse schooldays experiences and in the redemptive process that followed. The myriad cognitive, affective, physical and social elements that form the self make each individual unique (Mercer, 2014), and there are indeed many differences in the details of the two stories and in the personalities of their narrators, as they emerge from the narratives. Shanit faced her low point in elementary school; Tehila faced it in high school. Shanit was placed in a low-level group; Tehila was diagnosed with dyslexia. Shanit could enlist her parents' help; Tehila, from a weaker socioeconomic background, found the support she needed only as a young adult working in the US. Shanit teaches in a socioeconomically strong elementary school; Tehila teaches in a socioeconomically weak high school. Shanit seems to have been more determined than Tehila in identifying and pursuing her goals; she speaks of "running" and "jumping the way," while Tehila "rolls into" her profession unintentionally.

At the same time, there are striking thematic similarities between the two stories. Both Shanit and Tehila link the past and present in their narratives, going back and forth between them. Their past is a story of childhood/adolescence marked by the coexistence and eventual resolution of two identities: devotee of American popular culture on the one hand; illiterate, alienated student in the English classroom on the other. Both Shanit and Tehila display flexibility in their self-positioning during this period as they manage to maintain identity positions enabling them to advance their oral English, via songs and films, even as the 
identity imposed upon them by the education system temporarily destroys their motivation for literacy. This ability allows them to sustain the motivation which eventually leads each of them to the turning point of her narrative and the pattern of redemption which follows, culminating in a present reality of committed and fulfilling English teaching. The causal links which Shanit and Tehila create between the past and present reveal how strongly their identities are tied to their chosen profession, and how their pedagogical work draws on some of their most intimate and difficult memories. For both students, teaching transforms these memories into a springboard for current success and self-fulfillment, notwithstanding a lingering sense of grievance and pain.

Even as we admire these compelling stories of difficulties overcome and hard-earned success, it is worth addressing two possible caveats. The first has to do with what Bruner (1991) has called narrative's "embeddedness in genre" (p. 7), the tendency of narratives to follow general culturally-determined plotlines. As McAdams (2006) shows, the redemptive pattern of rising from adversity to achievement and generativity is a typically American storyline, embedded in American cultural products. Thus, the great influence of American culture and values on Israel, and particularly on those Israelis who have a strong attachment to this culture, could have influenced my students to adopt this pattern in their understanding and construction of their own life stories, in the episodes they chose for presentation and in the causal links they created. In other words, not only the content but the form itself of my students' narratives could be imbued with American influence. However, if this is so, it does not make their self-portrait less authentic; what it means is that the American-born image of the rags-to-riches hero has become one of the many cultural elements influencing, and here empowering, their evolving selves.

An additional social element possibly influencing the redemptive approach of the students is a more immediate contextual one: the contribution of the interview situation itself. As McAdams says, "stories are performed in the presence of certain audiences. Different situations call for different kinds of stories" (McAdams et al., 2006, p. 6); Riessman (2005) similarly claims that "audiences are implicated in the art of narrative performance" (p. 5). In the case of Shanit and Tehila's interviews, it might be conjectured that the students' knowledge that I, their interviewer, was the head of an English department may have influenced them to position themselves as particularly committed English teachers. I do not believe that the influence of this knowledge could have been very strong as I was not in a position of authority over these students or involved in the development of their careers. Nevertheless, the interview situation may have had some influence on the self-portrayal, and if so, one can only accept it as one of the many factors affecting the formation of the narrative and the narrative self in this case. 
Finally, I would like to draw attention to what I believe to be two important pedagogical implications of the experiences narrated by these student-teachers. First, both stories speak of the importance of a warm, encouraging, enabling learning environment in fostering self-efficacy in discouraged learners. This environment is found in Shanit's "home schooling" in the first story and in Tehila's years with her adoptive American "family" in the second. A large part of the stories' redemptive power lies in these scenes in which the acquisition of literacy suddenly becomes possible for the protagonists, constituting the turning point of their story, and in the final scenes in which they manage to recreate this environment in their classrooms, consciously breaking away from the "negligent" teaching which they themselves had endured. They thus remind us that a warm, supportive atmosphere is indispensable for successful teaching. Second, the two stories demonstrate the link between learning motivation and empowering identity positions and, in particular, Norton's (2014) observation that attachment to an imagined community of target-language speakers can offer such positions, possibly circumventing less enabling learning environments. As we have seen, the motivating power of this attachment drives the two narrators, making them autonomous learners par excellence as regards vocabulary acquisition, listening and oral skills. In connection with this, one vital insight to be drawn from the students' accounts has to do with the importance of acknowledging such learners' desire for cultural connection with the Other, a desire attested to in other studies as well (Kramsch, 2009; Takahashi, 2013; Tashma Baum, 2014).

In view of the instrumentalist and pragmatic focus in much current teaching of English as a foreign language (Block \& Cameron, 2002; Phipps, 2010; Ros i Solé \& Fenoulhet, 2013), I believe that developing teaching methods which would combine warmth and encouragement with intellectual stimulation geared to the dreams and desires of learners is the only adequate response to the difficult memories of Shanit and Tehila. Too often an artificial, deficient instructional setting, the EFL classroom could thus become, as Kramsch (2009) has put it, "a symbolic multilingual environment, where alternative realities can be explored and reflected upon" (p. 210), a space inviting and incorporating the expression of the student's manifold identity-positions. I believe that further research should be conducted into ways in which classroom teaching can successfully achieve this, both in terms of the encouragement of teachers' sensitivity to their students' complex identities and in the development of engaging learning materials responding to and enabling their expression (Dörnyei, 2009; Ibrahim, 1999; Kramsch, 2009; Phipps, 2010; Ros i Solé \& Fenoulhet, 2013; Ushioda, 2011; Wilson, 2013). Such teaching could promote students intellectually, emotionally and socially, both inside and outside the classroom, for teaching, in the words of Tehila, "has an effect, it affects everything," and just as it can destroy motivation and self-confidence, it can also be a tremendous force for the good. 
References

Bandura, A. (1997) Self-efficacy: The exercise of control. New York: W. H. Freeman. Bauer, J. J., McAdams, D. P., \& Pals, J. L. (2008). Narrative identity and eudaimonic well-being. Journal of Happiness Studies, 9, 81-104.

Bauman, Z. (2001). Identity in the globalizing world. In E. Ben-Rafael \& Y. Sternberg (Eds.), Identity, culture and globalization (pp. 471-482). Leiden: Brill.

Ben-Rafael, E. (1994). Language, identity, and social division: The case of Israel. Oxford: Clarendon.

Benson, P., \& Nunan, D. (Eds.). (2005). Learners'stories: Difference and diversity in language learning. Cambridge: Cambridge University Press.

Block, D., \& Cameron, D. (Eds.). (2002). Globalization and language teaching. London: Routledge.

Block, D. (2007). The rise of identity in SLA research, post Firth and Wagner (1997). The Modern Language Journal, 91, 863-876.

Bruner, J. (1987). Life as narrative. Social Research, 54(1), 11-32.

Bruner, J. (1991). The narrative construction of reality. Critical Inquiry, 18(1), 121. doi: $10.1086 / 448619$.

Bruner, J. (2002). Making stories: Law, literature, life. Cambridge, MA: Harvard University Press.

Coffey, S. (2013). Strangerhood and intercultural subjectivity. Language and intercultural communication, 13(3), 266-282. doi: 10.1080/14708477.2013.804532

Cohler, B. J., \& Hammock, P. L. (2006). Making a gay identity: Life story and the construction of a coherent self. In D. P. McAdams, R. Josselson, \& A. Lieblich (Eds.), Identity and story: Creating self in narrative (pp. 151-172). Washington, DC: American Psychological Association.

Creswell, J. W., \& Miller, D. L. (2000). Determining validity in qualitative inquiry. Theory into Practice, 39(3), 124-130.

Crystal, D. (1997). Dictionary of linguistics. Oxford: Blackwell.

Davies, B., \& Harré, R. (1990). Positioning: The discursive production of selves. Journal for the Theory of Social Behavior, 20(1), 43-63.

Donitsa-Schmidt, S. (2004). Lu rak yadati anglit - emdot oley hever hamdinot klapey hasafa ha'anglit [If only I knew English - the attitudes of immigrants from the former Soviet Union towards the English language]. $\mathrm{Ha}$ chinuch U'svivo, 26, 167-177.

Dörnyei, Z. (2009). The L2 motivational self system. In Z. Dörnyei \& E. Ushioda (Eds.), Motivation, language identity and the L2 self (pp. 9-42). Bristol: Multilingual Matters. 
Dörnyei, Z. (2014a). Future self-guides and vision. In K Csizér \& M. Magid (Eds.), The impact of self-concept on language learning (pp. 7-18). Bristol: Multilingual Matters.

Dörnyei, Z. (2014b, May). Motivation, vision and life narratives. Keynote speech at the conference Matters of the Mind: Psychology and Language Learning. Graz, Austria..

Giddens, A. (1991). Modernity and self-identity: Self and society in the late modern age. Cambridge: Polity.

Ibrahim, A. K. M. (1999). Becoming black: Rap and hip-hop, race, gender, identity, and the politics of ESL. TESOL Quarterly, 33(3), 349-369.

Kalaja, P., Menezes, V., \& Barcelos, A. M. F. (Eds.). (2008). Narratives of learning and teaching EFL. Basingstoke: Palgrave Macmillan.

Kramsch, C. (2009). The multilingual subject. Oxford: Oxford University Press. Labov, W. (2013). The language of life and death: The transformation of experience in oral narrative. Cambridge: Cambridge University Press.

Lieblich, A., Tuval-Mashiach, R., \& Zilber, T. (1998) Narrative research. Newbury Park, CA: Sage.

Lincoln, Y. S., \& Guba, E. G. (1985). Naturalistic inquiry. Newbury Park, CA: Sage. McAdams, D. P. (1993). The stories we live by: Personal myths and the making of the self. New York: William Morrow.

McAdams, D. P. (2001). The psychology of life stories. Review of General Psychology, 5, 100-122.

McAdams, D. P. (2006). The redemptive self: Stories Americans live by. New York: Oxford University Press.

McAdams, D. P., \& Bowman, P. J. (2001). Narrating life's turning points: Redemption and contamination. In D. P. McAdams, R. Josselson, \& A. Lieblich (Eds.), Turns in the road: Narrative studies of lives in transition (pp. 3-34). Washington, DC: American Psychological Association.

McAdams, D. P., Josselson, R., \& Lieblich, A. (2006). Introduction. In D. P. McAdams, R. Josselson, \& A. Lieblich (Eds.), Identity and story: Creating self in narrative (pp. 3-13). Washington, DC: American Psychological Association Press.

Mercer, S., Ryan, S., \& Williams, M. (Eds.) (2012). Psychology for language learning: Insights from research, theory \& practice. Basingstoke: Palgrave MacMillan.

Mercer, S. (2013). Working with language learner histories from three perspectives: Teachers, learners and researchers. Studies in Second Language Learning and Teaching, 3(2), 161-185

Mercer, S. (2014). A complexity perspective on the self. In S. Mercer \& M. Williams (Eds.), Multiple perspectives on the self (pp. 160-176). Bristol: Multilingual Matters. 
Mills, N. (2014). Self-efficacy in second language acquisition. In S. Mercer \& M. Williams (Eds.), Multiple perspectives on the self (pp. 20-36). Bristol: Multilingual Matters.

Narkiss, D. (2002). Anglit be'eynayim zarot [English through foreign eyes]. Te'orya Uvikoret 20, 228-259.

Norton, B. (2000). Identity and language learning: Gender, ethnicity and educational change (1st ed.). Harlow: Longman.

Norton, B. (2013). Identity and language learning: Extending the conversation (2nd ed.). Bristol: Multilingual Matters.

Norton, B. (2014). Identity and poststructuralist theory in SLA. In S. Mercer \& M. Williams (Eds.), Multiple perspectives on the self (pp. 72-88). Bristol: Multilingual Matters.

Oxford, R. L. (1995). When emotion meets (meta)cognition in language learning histories. International Journal of Educational Research, 23(7), 581-594. doi:10.1016/0883-0355(96)80438-1

Pals, J. L. (2006). Constructing the "springboard effect:" Causal connections, selfmaking, and growth within the life story. In D. P. McAdams, R. Josselson, \& A. Lieblich (Eds.), Identity and story: Creating self in narrative (pp. 175199). Washington, DC: American Psychological Association.

Pavlenko, A. (2001). Language learning memoirs as a gendered genre. Applied Linguistics, 22(2), 213-240. doi:10.1093/applin/22.2.213

Pavlenko, A. (2002). Narrative study: Whose story is it, anyway? TESOL Quarterly, 36(2), 213-218.

Pavlenko, A. (2003). "I never knew I was a bilingual:" Reimagining teacher identities in TESOL. Journal of Language Identity and Education, 2(4), 251-268. doi: 10.1207/S15327701JLIE0204_2

Pavlenko, A. (2007). Autobiographic narratives as data in Applied Linguistics. Applied Linguistics, 28(2), 163-188. doi:10.1093/applin/amm008

Pavlenko, A., \& Norton, B. (2007). Imagined communities, identity, and English language teaching. In J. Cummins \& C. Davison (Eds.), International handbook of English language teaching (pp. 669-680). New York: Springer.

Phipps, A. (2010). Drawing breath: Creative elements and their exile from higher education. Arts \& Humanities in Higher Education, 9(1), 42-53. doi:10.1177/1474022209350103

Polkinghorne, D. E. (1988). Narrative knowing and the human sciences. Albany: State University of New York Press.

Polkinghorne, D. E. (1990). Narrative and self-concept. Journal of Narrative and Life History, 1(2 \& 3), 135-153.

Riessman, C. (1993). Narrative analysis. Newbury Park, CA: Sage. 
Riessman, C. K. (2002). Analysis of personal narratives. In J. F. Gubrium \& J. A. Holstein (Eds.), Handbook of interview research: Context \& method (pp. 695-710). Thousand Oaks: Sage.

Riessman, C. K. (2005) Narrative analysis. In N. Kelly, C. Horrocks, K. Milnes, B. Roberts, \& D. Robinson (Eds.), Narrative, memory \& everyday life (pp. 1-7). Huddersfield: University of Huddersfield Press.

Riessman, C. K. (2008). Narrative methods for the human sciences. Thousand Oaks: Sage.

Ros i Solé, C., \& Fenoulhet, J. (2013). Romanticising language learning: Beyond instrumentalism. Language and Intercultural Communication, 13(3), 257265. doi: $10.1080 / 14708477.2013 .804531$

Shoaib, A., \& Dornyei, Z. (2005). Affect in lifelong learning: Exploring L2 motivation as a dynamic process. In P. Benson \& D. Nunan (Eds.), Learners' stories: Difference and diversity in language learning (pp. 22-41). Cambridge: Cambridge University Press.

Smooha, S. (2004). Jewish ethnicity in Israel: Symbolic or real? In U. Rebhun \& C. I. Waxman (Eds.), Jews in Israel: Contemporary social and cultural patterns (pp. 47-80). Lebanon, NH: Brandeis University Press.

Spolsky, B., \& Shohamy , E. (1999). The languages of Israel: Policy, ideology and practice. Clevedon: Multilingual Matters.

Takahashi, K. (2013). Language learning, gender and desire: Japanese women on the move. Bristol: Multilingual Matters.

Tashma Baum, M. (2014). "The aspect of the heart:" English and self-identity in the experience of preservice teachers, Language and Intercultural Communication, 14(4), 1-16. doi: 10.1080/14708477.2014.934379

Tse, L. (2000). Student perceptions of foreign language study: A qualitative analysis of foreign language autobiographies. The Modern Language Journal, 84(1), 69-84. doi: $10.2307 / 330450$

Ushioda, E. (2009). A person-in-context relational view of emergent motivation, self and identity. In Z. Dörnyei \& E. Ushioda (Eds.), Motivation, language identity and the L2 self (pp. 215-228). Bristol: Multilingual Matters.

Ushioda, E. (2011). Motivating learners to speak as themselves. In G. Murray, X. Gao, \& T. Lamb (Eds.), Identity, motivation and autonomy in language learning (pp. 11-24). Bristol: Multilingual Matters.

Wilson, R. (2013). Another language is another soul. Language and Intercultural Communication, 13(3), 298-309. doi: 10.1080/14708477.2013.804534 